\title{
The Environmental Education in Teachers' Initial Training of and the Seven Complex Lessons of Morin: Contributions and Challenges
}

\author{
Daniele Saheb, Daniela Gureski Rodrigues, Mirian Celia Castellain Guebert \\ PPGE, PUCPR, Curitiba, Brazil \\ Email: danisaheb@yahoo.com.br
}

How to cite this paper: Saheb, D., Rodrigues, D. G., \& Guebert, M. C. C. (2017). The Environmental Education in Teachers' Initial Training of and the Seven Complex Lessons of Morin: Contributions and Challenges. Creative Education, 8, 447460 .

https://doi.org/10.4236/ce.2017.83034

Received: February 20, 2017

Accepted: March 28, 2017

Published: March 31, 2017

Copyright $\odot 2017$ by authors and Scientific Research Publishing Inc. This work is licensed under the Creative Commons Attribution International License (CC BY 4.0).

http://creativecommons.org/licenses/by/4.0/

\begin{abstract}
The National and International Policies, through events and documents, stimulate or determine the insertion of the Environmental Education (EE) in the curriculum of Basic Education and Higher Education in Brazil. In June 2012, it was published the National Curricular Guidelines of EE, which are mandatory and reaffirm important aspects present in the debates on the theme in the country since 1990 with the National Environmental Education Policy (NEEP). Based on this assumption, this research aims to discuss the insertion of the Environmental Education in the teacher's training of Initial Years. To do so, it discusses the understanding of Environmental Education and teacher's training. The field research was carried out in the undergraduate course in Pedagogy of a public university in the city of Curitiba, Paraná, responsible for the training of mostly state teachers since 1938. As a data collection instrument, it was used the documentary research, which was based on the Political Pedagogical Project of the Pedagogy Course (2007) and the interview with the teacher's trainers. From the data analysis, the disciplines and the EE conceptions from the teachers were characterized in their epistemological aspects, since they guide their own pedagogical practice, and analyzed based on the ideas of the Complexity of Morin (2001), especially in the work Seven Complex Lessons in Education of the Future (2001). It is possible to affirm that the premise of the EE in the perspective of complexity has not taken place in the university yet and that it is necessary to invest in this process to contribute to the overcoming of the seven "holes" in education identified by Morin along with the construction of his work. The seven complex lessons in education for the future are important ingredients for the thought reform and therefore, for the Environmental Education.
\end{abstract}

\section{Keywords}

Environmental Education, Teacher's Training, Complexity, Morin, Seven Complex Lessons in Education for the Future 


\section{Introduction}

In order to contribute to the discussion on the Environmental Education (EE), a prevailing question has now been raised: the teachers' training for pedagogical practice in schools, through university education. The National and International Policies, through events and documents, stimulate or determine the insertion of $\mathrm{EE}$ in the curriculum of Basic Education and Higher Education in a transversal way, which is, crossing the different disciplines. In Brazil, in June 2012, it was published the National Curricular Guidelines of EE, which are mandatory and reaffirm important aspects present in the debates on the theme in the country since 1990 with the National Environmental Education Policy (NEEP).

There is an agreement that confronting socio-environmental issues is one of the most important challenges to humanity, and in one way or another, to a greater or lesser extent, its consequences are already affecting life on the planet. The crisis created, resulting from the impact of human action on the environment, imposes the necessity to build a new relationship that overcomes this dichotomy in favor of the common good, the objective of Environmental Education. Faced with these new requirements, the teacher's role is highlighted, since he/she is the professional responsible for the development of EE in school, which he/she does base on his/her conceptions and knowledge. It is important to emphasize the importance of the teachers' training course at the university to overcome the difficulties and weaknesses of pedagogical practice in this area. This article analyzes this preparation in the undergraduate course in Pedagogy of a public university in the city of Curitiba, Paraná, responsible for the formation of mostly state teachers since 1938. Initially the documentary research was carried out through the Political Pedagogical Project (2007) aiming to identify the themes of EE in the subjects' syllabus. Next, it was held interviews with five teachers of the course. From the data analysis, the disciplines and the EE conceptions from the teacher's trainers were characterized in their epistemological aspects, since they are the ones that guide their pedagogical practice. The reflections and the perspectives on the social and environmental issues are built within a network of meanings and correlations. Therefore, the characteristics were analyzed based on the ideas of the Complexity of Morin (2001), especially in the work Seven Complex Lessons in Education for the Future (2001). It is possible to affirm, through this study, that the premise of EE in the paradigm of complexity has not taken place in the university yet, and it is necessary to invest in this perspective in order to contribute to overcoming the seven "holes" in education identified by Morin along with the construction of his work. The seven complex lessons in education for the present and the future are important ingredients for the thought reform.

The purpose of this study was to analyze the EE conceptions of the teacher's trainers in early years of Elementary Education through the seven lessons of Morin. In this way, it proposes the reflection first from the focus of the EE based on the Complexity of Morin. It then presents the methodology and analysis of the data and finally the results and conclusion. 


\section{Environmental Education and Complexity}

There are many trends and representations of Environmental Education, each with their own paradigms. We believe that knowing them and understanding them is necessary because the way the teacher approaches and presents them in the classroom has repercussions on the construction of their representation by the student.

In addition, it facilitates the identification of convergences and divergences in research contexts and pedagogical interventions, subsidizing discussions and reducing the risks of deforming reality (SAUVÉ, 2005). Among the trends of Environmental Education, which are in line with the paradigm of complexity that underlies the research presented here, we highlight the critical, systemic, humanist, and moral and ethical perspectives.

The critical perspective presupposes a broad dialogue among education, society and nature, markedly by Freirean thinking about the models of relationships and socio-environmental mediations that constitute us as individuals. With Freire (2002: p. 42) we understand that reflection is the movement between doing and thinking, between thinking and doing, which is, "thinking to do" and "thinking about doing". The interdisciplinary dialogue allows the complexity of the reality and the socio-environmental problems to be evidenced.

[...] The extreme urgency of this reconception of man and society, no longer situating itself in a cognitive-technological confrontation with nature, but inserting itself in a diagnostic-interpretative dialogue, had as incisive moment the bankruptcy of the economistic rationality Neoclassical [...]. In this connection, Our Common Future, also Report Brundtland, 1987 proposes sustainable development social equity and ecological balance ... (CARNEIRO, 2006: p. 24).

This way, the critical trend emphasizes learning and collective solutions in the educational environments of mobilization, reaffirming that education takes place in the relation (GUIMARÃES, 2004). In addition to this, the systemic vision highlights the contributions of ecology and aims to overcome the environment fragmental vision and highlights the socio-environmental interdependence. The dialogue among environment-society-nature includes in the process the category of culture that characterizes the humanist current, based on the Human and Social Sciences, as well as Geography, its local contexts, its dynamics, and its symbolic components. The understanding that the various trends are not exclusive and have in common the foundation of the relation (man/womansociety-nature-culture-environment) shows that Environmental Education is also designated to the construction of socio-environmental values, that is, moral and ethical order. Although Leff (2001: p. 18) states that "[...] the environmental crisis is a crisis of reason, of thought, of knowledge" and "environmental degradation, the risk of ecological collapse and progress of inequality and poverty are eloquent signs of the crisis of the globalized world “(p. 9).

In Brazil, it is evidenced less by actions and more by official documents such 
as Law $n^{\circ} .9 .795 / 99$, which established the National Environmental Education Policy (NEEP) and determines the presence of EE in all levels of formal education, including Higher Education aiming the training of professionals, Resolution $\mathrm{n}^{\circ}$. 2, from June 15, 2012, which establishes the National Curricular Guidelines for the Environmental Education-NCGEE, EE appears as an essential component to minimize socio-environmental problems, from a complexity perspective.

The seven complex lessons proposed by Morin, originally as necessary to the future of education (2001), therefore, also to the specificity of Environmental Education, currently validated as necessary for the education of the present (Moraes apud Almeida, 2012) called: Detecting error and illusion; Principles of pertinent knowledge; Teaching the human condition; Earth identity; Confronting uncertainties; Understanding each other; Ethics for the human genre, do not present themselves as a solution to the environmental crisis, but as a way for all those who think and do education, offering basic reflections to EE (SAHEB, 2013).

Reigota's work on social representations of the environment (1995) shows the relation of the environmental representations of teachers and the EE models present in their pedagogical practices, endorsing the Complexity Paradigm when referring to EE. "Complex systems have a double characteristic: to be integrated by heterogeneous elements, in permanent interaction, and to be opened, that is, submitted as totality" (GARCIA apud REIGOTA, 1995: p. 18).

This requires, in the perspective of complexity, the "thinking reform" (MORIN, 2001), capable of concretizing an Education for the Planetary Age, in which "the history of human life is marked by innovations and creations whose impacts lead mankind to development and economic crises. The planet becomes increasingly interdependent (Morin, Ciurama, \& Motta, 2003: p. 11).

Reforming the thinking requires of the individual inserted in a historical socio-historical time other conceptions of life, of relation environment-societynature, of world, of education and that reflect in its way of acting-to-think-in the world. The questions that are imposed become multiple and there is no longer a single truth. Thus, the conception of EE is also reformed and the disputes are exchanged for dialogues woven among different areas, revealing other possible epistemological paths (Morales, 2007), embracing the socioeconomic, political, cultural, historical, affective emotional, pedagogical, contextualized to local, regional and global realities (Dias, 2001). Floriani \& Knechtel (2003) remind us that crises allow cognitive responses beyond scientific rationality, reaching an environmental rationality. This way, EE ignites to a level of human formation of socio-environmental values that, through complex thinking, mobilizes the reflexive action of ethical thinking-acting. Almeida (2008: p. 44), paraphrasing Morin, recalls that we live between the "alternative of the metamorphosis of society or its catastrophe". As teachers and researchers in EE as we are, we understand this risk because we know that environment, society and nature are part of the same planetary phenomenon. 
The ecology of knowledge proposed by Moraes (2008) reaffirms the interdisciplinary and transdiciplinary character of Environmental Education that, through complexity, is woven together between scientific and humanistic knowledge, academic and popular knowledge, between the whole and the parts, respecting cultures, contexts, histories and relations, to reach a level of education that awakens to a "world-society" (Almeida, 2008: p. 44). Complexity, however, requires a process of ethical reconnection of knowledge that Morin describes in stages: Self-ethics (the individual ethics that must lead to one ethic for the other); The socio-ethics (of the community that precedes it, encompasses it, and transcends it); Anthropo-ethics (of the species facing its destiny in the planet) (Petraglia, 2010: p. 39).

Although the academic production on the complexity of Environmental Education is in the process of consolidation, the references to Morin's contributions on the subject appear in national and international subjects, outlining a path with no return to its comprehension as paradigmatic change that opposes epistemology reductionist approach to environmental knowledge. The Complexity Paradigm is still marginal in scientific, epistemological, and philosophical thinking (Morin, 2010) and must be conceived as a challenge in the initial and permanent formation of teachers to, as well as the incompleteness of the human being (Freire, 2002), let us think of incompleteness of knowledge rather than its mutilation (Morin, 2010) that makes it difficult to understand the complexity of the real.

The environmental problem is increasingly multidimensional and planetary, therefore systemic, impossible to be solved by the modern paradigm of simplification. Complex problems require complex solutions, so complexity paradigm presents itself as a possible epistemological path to rethink the way science presents itself in the face of planetary crises (Santos, 2002).

In his book, Science with Consciousness (2010), Morin uses metaphors and analogies to explain the paths of complexity, describing them as "avenues that lead to the challenge of complexity" (2010: p. 177) whose names are chance and disorder, transgression, complication, organization and recursion, which coexist an eventual complementarity between them. Viégas (2002) reminds us of the inexistence of an absolutely determined world, under the exclusive bias of order, as well as a random world, considered only from the idea of disorder. They would both be poor and mutilated worlds; The first, unable to evolve, and the second, to be born (Morin apud Viégas, 2002: p. 84). Thus, concepts of order, disorder, and organization can only be conceived regarding each other and through mutual interactions. For complexity, the relation order/disorder, considered repulsive and opposed to the simplifying and reductionist science, becomes communicating and complementary, being the core for the development of the world. In this scenario, reflecting on the teacher's formation and the environmental educator from the complexity paradigm is to react to the models that present fragmented, disjunctive, exclusionary and reductionist science in the face of complex situations, such as socio environmental issues. 
Morin (2010: p. 31), when proposing to educators the thought reform seeking the complex thinking, understands that one of the purposes of education is to provide students with "a culture that allows them to articulate, reconnect, contextualize, situate themselves in the context and, if possible, to globalize, to gather the knowledge they have acquired". And it depends on the teacher's performance, so the urgency of reforms in your thinking, feeling and acting both inside and outside the classroom. Knowing is conditioned to being, in the same way that being is conditioned to knowing. The action of knowing "is present simultaneously in biological, cerebral, spiritual, cultural, linguistic, social, political and historical actions [...]" (Morin apud Petraglia, 2010: p. 81). Other authors corroborate this cognitive conception, such as Maturana and Varela (1995) and Capra (2001) who argue that cognition, learning and life are not separated. In his conception of complexity, for Morin, the act of knowing includes the human experiences and actions associated with emotion, such as passion, pain, and pleasure, affecting and letting itself to be affected by it, so that education can “transform knowledge into wisdom" (2006: p. 47).

The teacher's training in the epistemological and methodological aspects proposed by the seven complex lessons in education of the future (Morin, 2011) involves aspects of the political, economic, social, and cultural spheres, in an articulated and integrated way. It focuses on the complexity in Education and, due to the complexity of Environmental Education. This choice, on the other hand, makes the thought reform into a complex thinking capable of helping citizens to face ethically the environmental problems of their time.

On the teacher's formation to act in front of the complexity of the Environmental Education, we include here four perspectives presented by Sacristán \& Gómez (1998), whose specificities do not prevent their parts from constituting a complex whole: the academic, technical, practical, and social reconstruction perspectives. In the academic perspective, the focus is on the teacher's specialty in relation to the discipline of acting or some thematic approach; In the technical perspective, the emphasis is on the technical domain of the applications of scientific knowledge, that is, on the technical performance of the professional, a procedure that can be called technical rationality; In a practical perspective, the focus is "learning from practice, from practice and from practice" (p.363); In the perspective of social reconstruction, the emphasis is on teaching as a critical and ethical activity, whose intentionality lies in the construction and development of values. The complexity perspective does not exclude any of the presented skills and seeks their interaction in a harmonious whole in the process of reconnecting knowledge from a transdisciplinary effort, breaking with the dualities and the separation between nature and culture.

\section{Methodology}

The field research was of a qualitative nature and was being delineated during the development of the work. For this, we used the following methodological organization: 
a) The bibliographical research, anchored in the dialogue with the works of Edgar Morin, highlighting the seven complex lessons in education for the future (2001), as well as other authors whose research converges to the complexity of Morin and Environmental Education. This stage made it possible to broaden the reflection about teacher's training under the focus of the dialogue between complexity and the socio-environmental theme.

b) The field research was developed from the analysis of the Political Pedagogical Project of the Pedagogy course of a public university in Curitiba, Paraná, which has been training teachers since 1938. The syllabus of all the disciplines was analyzed to identify aspects related to social and environmental themes. From then on, 5 teachers were selected for the interview. The selected ones are graduated in Biological Sciences, Social Sciences, and Pedagogy. The professional experience in teaching varies from 08 to 32 years, three of them with doctorate degree and two with post-doctorate, aged between 42 and 68 . The interviews contained questions organized from categories that correspond to Morin's seven lessons and were conducted individually. Each interview lasted about 4 hours.

Table 1 systematizes the organicity of the data collection and analysis process. Thus, in the first column on the left we find the number that corresponds to the data analysis categories; the second column on the left brings the categories

Table 1. Interview questions.

\begin{tabular}{|c|c|c|c|}
\hline N. & Lessons & Key-words & Question \\
\hline 1 & $\begin{array}{l}\text { Detecting error } \\
\text { and illusion }\end{array}$ & - Illusion & $\begin{array}{l}\text { - What do you understand by blinding paradigm? Exemplify. } \\
\text { The classes at the University. } \\
\text { - During the initial formation of the teacher is it important to } \\
\text { consider subjectivity? Why? } \\
\text { - Do the blindness and error contribute to overcome illusion? Why? }\end{array}$ \\
\hline 2 & $\begin{array}{c}\text { Principles of } \\
\text { pertinent knowledge }\end{array}$ & $\begin{array}{l}\text { - Context } \\
\text { - Fragmentation }\end{array}$ & $\begin{array}{l}\text { - Is it important to contextualize information during class? If so, how? } \\
\text { - What do you understand by fragmentation of knowledge? } \\
\text { Do you seek to overcome the fragmentation of knowledge in your classes? How? }\end{array}$ \\
\hline 3 & $\begin{array}{l}\text { Teaching the } \\
\text { human condition }\end{array}$ & $\begin{array}{l}\text { - Several languages } \\
\text { - Human Condition }\end{array}$ & $\begin{array}{l}\text { - In your classes, do you use movies, music, art or literature as a methodology? } \\
\text { How? Why? } \\
\text { - Besides the cognitive dimension, what other dimensions of the } \\
\text { learner should be considered in the process? }\end{array}$ \\
\hline 4 & Earth identity & $\begin{array}{l}\text { - Quality of life } \\
\text { - Human Relations } \\
\text { and solidarity }\end{array}$ & $\begin{array}{l}\text { - Do you believe that the course works with socio-environmental issues? } \\
\text { How? Why? } \\
\text { - Are the human relations a concern during the development of the discipline? }\end{array}$ \\
\hline 5 & $\begin{array}{l}\text { Confronting } \\
\text { uncertainties }\end{array}$ & $\begin{array}{l}\text { - Uncertainty } \\
\text { - Unpredictable reality }\end{array}$ & $\begin{array}{l}\text { - Does the University work with strategies that accept the uncertainties, } \\
\text { the novelties, the unexpected, the new? Why? } \\
\text { - In your teaching practice, do you always have control of the planned actions? } \\
\text { Explain. }\end{array}$ \\
\hline 6 & $\begin{array}{l}\text { Understanding } \\
\text { each other }\end{array}$ & $\begin{array}{l}\text { - Intellectual understanding } \\
\text { - Subjective human } \\
\text { understanding }\end{array}$ & $\begin{array}{l}\text { - Do your classes contribute to understanding life? } \\
\text { - Do the curriculum disciplines of the course in which you } \\
\text { work help the student to understand the world and himself? How? }\end{array}$ \\
\hline 7 & $\begin{array}{l}\text { Ethics for the } \\
\text { human genre }\end{array}$ & $\begin{array}{l}\text { - Respect for diversity } \\
\text {-Democracy }\end{array}$ & $\begin{array}{l}\text { - Do the teaching of coexistence with respect and tolerance } \\
\text { permeate in some way your classes? } \\
\text { - In your classes, are there situations that work ethics? Why? How? }\end{array}$ \\
\hline
\end{tabular}

Source: Saheb, 2013: p. 118-119. 
of analysis that correspond to the paradigm of complexity proposed by Edgar Morin; The third column presents the keywords or indicators that allowed the maintenance of the categories chosen a priori; The fourth column presents the questions that were formulated in the interview and that relate to each of the categories of analysis. In the documentary analysis to assist the interpretation and discussion of the data collected, it was included the Pedagogical Political Project (PPP) of the Pedagogy Course (2007).

\section{Some Findings, Limits, and Possibilities}

The work The Seven Complex Lessons in Education for the Future was chosen as a reference matrix to reflect on the complexity of Environmental Education and teacher's training as a rich study that exposes essential problems facing education in the 21st century. Although it is not a model and not even a set of rules or guidelines on what and how to teach, it was nominated and used in different countries of Europe, Latin America, the United States, Canada and, in 2012, was the theme of an International Conference held in Fortaleza, Ceará, in commemoration of the ten-year launch of the work. In its origin, "every society and in every culture, without exclusivity and rejection, according to models and rules proper to each society and to each culture" was indicated (Morin, 2001: p. $15)$.

The ideas developed by Morin through the Seven Lessons constitute an epistemological and methodological proposal that points out ways to the challenge of the EE in the scope of Formal Education.

Thus, the cognitive operators proposed by Morin are essential for the construction of a complex thinking, being capable of understanding and acting in the world in the face of the current crisis.

Based on the results of this research, it is possible to affirm that the discourse of the trainers demonstrated aspects convergent with Morin's Seven Lessons, although four out of the five teachers interviewed reported not having read the work yet. It was also found that trainers acknowledge the emergence of a reform in the teacher's training process and that they consider the Seven Lessons to be a significant contribution to transformation.

At the same time, teachers claim to believe that most of the education holes pointed out by Morin have not been surpassed yet by the university and continue to be reproduced through the teachers themselves, which have crystallized the presence of a reductionist and conservative thinking.

Although the teachers' statements show convergences with the Seven Lessons and, therefore, with Complexity, the reports revealed that in relation to the methodology the conservative practices characteristic of the university still predominate. However, it should be noted that some teachers mentioned in their testimonies the development of differentiated practices, which happens eventually.

Through the observation, it was possible to verify that although the Seven Lessons of Morin were identified in the discourse of the trainers and in the documents, that establish the guidelines of the courses studied, in the same for- 
mation process, there are teachers who practice practices that meet the Seven Lessons of Morin and others who act conservatively.

In this sense, it is important to emphasize that regarding the teaching of the first lessons, detecting error and illusion, the teachers' statements emphasized the importance of the cognitive dimension, that is, the attitude of thinking about the questions that involve thinking and learning. They also discussed the need for recognition of individual conceptions and the need to raise awareness about the learning that has been built along the professional and academic trajectory. Based on the interviewees' answers, it was observed that both teachers perceive the "hole" of the knowledge blindness as a component of the university formation process, at the same time as they promote attempts in their pedagogical practices towards addressing this problem. The documents' analysis also verified this.

Regarding the pertinent knowledge teaching, it was noticed that both the documents and the teachers' discourses show aspects convergent with interdisciplinarity, which nourishes the principle of pertinent knowledge, as a mean of reforming the thought, and therefore essential for the process of teacher's training in EE. However, although the National Curricular Guidelines for the Pedagogy Course (2006) and the Political Pedagogical Project of the Course (2007) predict interdisciplinarity based on the pedagogical training process, in the eyes of the Pedagogy Course teachers there are expressive difficulties that prevent the development of an interdisciplinary practice, among them, it was highlighted in the teachers' statements, the relation of the teachers themselves with the knowledge, as well as the predominance of a Cartesian thought. In this sense, all teachers of the Pedagogy Course interviewed referred to the fact that many teachers of the course consider themselves proprietors of the knowledge that they teach in their discipline and others consider their area to be hierarchically superior to the others. In addition, all were unanimous in emphasizing that they do not hold meetings to discuss methodological or pedagogical issues.

Regarding the human condition teaching, it was observed that teachers, despite being formed by a process organized by the disciplinarity and the emphasis on the reason to the detriment of other aspects that make up the human being, they recognize the importance of teaching the human condition on the educators' training. Some of them have already even inserted into their pedagogical practice, resources that enable them to work with dimensions other than cognitive dimensions. Another issue realized by the trainers is the need for pedagogical work that contemplates diversity and multiculturalism, which is also present in EE documents and in the PPP of the Pedagogy course.

The teaching of the earth identity is still a challenge during the formation in Pedagogy. It is believed that this is since a reductionist curriculum still prevails, which disregards social, political, environmental aspects as a basis in the pedagogy formation. The objective of changing individual and collective behaviors to produce transformations is recurrent in teachers' speech, however, when the practice is questioned, few of them can exemplify how they develop these reflec- 
tions in their pedagogical practice. Most of the professors have mentioned, in the questions, that they involve this knowledge in specific situations, that is, in exhibitions on subjects such as sustainability, globalization, and consumption. This occurs only when these themes are part of some discussions, but they all agree that this small approach is not enough for the teacher's training process in EE. However, in the elective subjects directed to the EE, one of them can affirm that the themes regarding the teaching of the earth identity are present throughout its development.

The understanding each other theme was considered a necessary knowledge for the teachers' formation who have the challenge of contributing, through education, for the construction of a more fair and equal society. Therefore, recognition and dialogue with the different world readings is a necessary condition for the teachers' training, regarding the socio-environmental theme. This way, we should also point out that the aspects related to this knowledge identified in the PPP of the Pedagogy Course are not sufficient to ensure its development during training. The interviewed teachers' speech showed that the insertion of this knowledge into the educators' formative process is still a challenge, which, as we have identified, presents as a first obstacle to the teachers themselves. This happens by the difficulty to retrieve in the interviewees' speeches the theoretical or practical situations that demonstrate the reflection on the comprehension teaching in Morin's perspective.

Despite the ethics, Morin's seventh lesson, to be in the documents that guide the Pedagogy Course, it is approached by the teachers through presentations, and integrate the discussions on some implicitly subjects. However, this practice does not correspond to Morin's proposal, developed in the Seven Lessons on the ethics teaching.

In summary, it is believed that yet embryonic, some of the Seven Lessons of Morin (2001) are present in the teachers' formation. This occurs through some teachers' conceptions, which permeate the discussions and subjects of study. It should be noted, however, that this does not occur in a homogeneous way, and that sometimes even the work focused on convergent aspects with the Seven Lessons as well as the EE, exists in the process of the teacher's training on behalf of a specifically teacher, fact which shows that the training proposed in this study is a great challenge.

In addition to the questions pointed out, another finding was that, although the trainers' teachers demonstrate affinity with the dimensions present in Morin's Seven Lessons and with the EE, there is an important difficulty regarding the didactic ${ }^{1}$ transposition of knowledge.

${ }^{1}$ The Didactic Transposition is the passage from scientific knowledge to taught knowledge. Such passage, however, should not be understood as the transposition of knowledge in the narrow sense of the term: only a change of place. This passage is supposed to be a process of transformation of knowledge, which becomes another in relation to the knowledge destined to teach. The term was introduced in 1975 by the sociologist Michel Verret and rediscussed by Yves Chevallard in 1985 in his book The Transposition Didactique. 


\section{Conclusion}

The present study is inserted in the environmental theme focusing on the teacher's education from the Complexity of Edgar Morin, especially regarding the work The Seven Complex Lessons in Education for the Future. The theoretical aspects initially presented clarify the conceptions that guide this study and that have facilitated the dialogue between the conception of complexity present in Edgar Morin's work and Environmental Education, regarding the process of teacher's training. The field research reported allows us to analyze if the seven lessons proposed by Morin are present in the conceptions and pedagogical practice of the trainers, within the scope of the initial formation in the University.

For the field research, we used the qualitative perspective of research together with the Pedagogy Course, from the same public university, with two data collection procedures, the interview, and the documentary analysis (Pedagogic PPP). We conclude the article without intending to present a conclusion about the proposed theme, but rather to propose reflections and stimulate the development of other studies in the perspective of complexity in relation to Environmental Education. In this sense, we find that the seven lessons of Morin constitute an important legacy that offers subsidies to the teacher's training, both regarding the curricular aspects orientation and the pedagogical practice for critical EE, focused on the environmental issues problematization from the life of the subjects involved in their contexts.

Although the complex thinking and the seven lessons are present in the speeches of the teacher's trainers and in occasional and sporadic practices, that is, in activities eventually carried out, they are still insipid. The reports on pedagogical and environmental practices revealed that, despite solitary and occasional attempts, the conservative teaching model based on Cartesian and reductionist thinking, characteristic of the Brazilian University, still prevails. However, we identified conceptions in the environmental field consistent with the seven lessons, even in four teachers who revealed that they did not know the work of Edgar Morin.

One relevant finding that we consider worrying is the absence of dialogues, discussions, and theoretical-methodological reflections among the pairs of the Pedagogy Course. Thus, the absence of meetings between the teaching staff is detrimental to the group integration, an important condition in the process of the teacher's training in the perspective of this study. Thus, practices that approach the paradigm of complexity coexist with conservative and fragmented practices. One of the participants in the survey reported that this was a frequent questioning presented by the students in the evaluations. These facts demonstrate the fragmentation between theory and practice and the distance from the transitional model to complex thinking and the ecology of socio-environmental knowledge.

However, we believe that openness to dialogue with the scientific and philosophical foundations converging with Morin's Complexity, which is possible for the interviewed teachers, is an important element on the path to the transforma- 
tion towards the construction of complex thinking. This path implies on a bold, persistent, and intentional attitude, that is, a process of mobilization from the complex thinking in search of the thought reform that, first, needs to be apprehended by the teacher to later be taught and experienced to the students. It is a path that involves an epistemological and reflective character. The teachers participating in the research recognize education as a natural and indispensable means for major paradigmatic changes, including lifestyles and ways of relating to environments. On the other hand, they recognize that the Brazilian education model does not fulfill this role, where the difficulties are structural, precarious of work, misconceptions, from Basic Education to Higher Education. We need another education system based on complexity. We agree with Morin (2013: p. 192) that "there is an increasing lack of education in facing the fundamental and global problems of the individual, of the citizen, of the human being. [...] They demand a complex way of thinking."

Environmental Education has been discussed about its ideal form of insertion in school: as a discipline, compulsory or not, as an interdisciplinary content or even as a transversal theme to the school curriculum. But it should be noted that all trainers agreed that EE should have its insertion as a compulsory or optional discipline in the teacher's training process. Even acknowledging their interdisciplinary nature, they emphasized the need for a specific approach to EE, under the risk that this dimension would not be effectively worked out during training, due to limiting factors such as the curriculum that determines the contents, and even, the lack of preparation of the teachers themselves. The teacher's trainers also stated that they believe that current teacher's education does not provide the relevant knowledge needed to promote EE in school.

The research showed that the Course of Pedagogy, field of research presented, although it offers three optional subjects that involve the socio-environmental theme, it does not contribute consistently with the teacher's training for Environmental Education. Although the Political Pedagogical Project of the course registers the presence of the theme during the formation, in practice, the training is restricted to a small number of students.

We recognize that breaking away from the conservative teacher's training models requires effort and involvement from everyone involved, as well as from the society that offers the demand and receives the investment results. The reflection must accompany the process operationalization, whose methodological procedures must be open to the needs and emergencies of the present time. However, the present research that supported this study made it possible to verify that initial teacher's education requires a university reform of a conceptual, methodological and curricular nature, possible with the thought reform, abandoning the fragmented practice, the linear reading of the world and environmental problems for a complex perspective, of knowledge reconnection, diversity dialogue.

The EE teacher's training in the perspective of complexity is based on the practice of self-criticism, ethics, care and commitment to full life on a planetary 
level, responsibility towards environmental sustainability and respect for diversity, recognizing the possibilities of the human condition as well as its limits. The paradigm of complexity is inclusive and relational par excellence.

It is possible to affirm, from this study that had as a research focus a teacher's training course involving the environmental theme, that the premise of $\mathrm{EE}$ in the paradigm of complexity is not materialized yet in the University and we must invest in this perspective in order to contribute to overcoming the seven "holes" in education identified by Morin during the construction of his work. The Seven Complex Lessons in Education for the present and the future are important ingredients for thought reform.

\section{References}

Almeida, C. (2008). Edgar Morin: A Thinker Who Witnesses His Time. In A. Pena-Vega, C. Almeida, \& I. Petraglia (Eds.), Edgar Morin: Ethics, Culture and Education. Sao Paulo.

Brazil (2012). National Curriculum Guidelines of Environmental Education. Brasilia Brazil.

Capra, F. (2001). The Web of Life: A New Scientific Understanding of Living Systems (6th ed.). Sao Paulo: Anchor.

Carneiro, S. M. M. (2006). Epistemological-Methodological Fundamentals of Environmental Education. Educar em Revista, 27, 17-35.

http://www.scielo.br/pdf/er/n27/a03n27.pdf

Dias, G. F. (2001). Environmental Education: Principles and Practices. São Paulo.

Floriani, D., \& Knechtel, M. R. (2003). Environmental Education: Epistemology and Methodologies. Curitiba.

Freire, P. (2002). Pedagogy of Autonomy: Knowledge Necessary for Educational Practice. Rio de Janeiro.

Guimarães, M. (2004). Environmental Education: From Form to Action. Campinas.

Leff, E. (2001). Environmental Epistemology. Sao Paulo.

Maturana, H. R., \& Varela, F. (1995). The Tree of Knowledge: The Biological Bases of Human Understanding. Campinas.

Moraes, M. C., \& Almeida, M. C. (2012). The Seven Complex Lessons in Education for the Present: For a Transformative Education. Rio de Janeiro.

Moraes, M. C. (2008). Eco-Systemic Thinking: Education, Learning and Citizenship in the 21st Century. Petropolis.

Morales, A. G. M. (2007). The Formation of the Professional Environmental Educator: Reflections, Possibilities, and Findings in the UFPR Specialization Course. Thesis, Curitiba.

Morin, E. (2013). The Road to the Humanity Future. Rio de Janeiro.

Morin, E. (2001). The Seven Complex Lessons in Education for the Future. Sao Paulo.

Morin, E. (2010). Science with Conscience (6th ed.). Rio de Janeiro.

Morin, E. (2011). The Well-Done Head. Rio de Janeiro.

Morin, E., Ciurama, E., \& Motta, R. D. (2003). Educating in the Planetary Age: Complex Thinking as a Method of Learning through Human Error and Uncertainty. Sao Paulo.

Petraglia, I. (2010). Edgar Morin: Education and Complexity of Being and Knowledge. 
Rio de Janeiro.

Reigota, M. (1995). Environment and Social Representation. Sao Paulo.

Sacristán, S. J., \& Gomez, P. (1998). Understanding and Transforming Teaching. Porto Alegre.

Saheb, D. (2013). The Socio-Environmental Knowledge Required for the Education of the Present and the Formation of the Environmental Educator under the Focus of Complexity. Thesis, Curitiba: Federal University of Parana.

Santos, B. S. (2002). A Discourse on the Sciences. Port.

Sauvé, L. (2005). A Cartography of Currents in Environmental Education. In M. Sato, \& I. C. M. Carvalho (Eds.), Environmental Education: Research and Challenges. Porto Alegre.

Viègas, A. (2002). Environmental Education in School Contexts: Beyond Comprehension Limitation and Discursive Incapacity. Dissertation, Niterói: Fluminense Federal University.

Submit or recommend next manuscript to SCIRP and we will provide best service for you:

Accepting pre-submission inquiries through Email, Facebook, LinkedIn, Twitter, etc. A wide selection of journals (inclusive of 9 subjects, more than 200 journals).

Providing 24-hour high-quality service

User-friendly online submission system

Fair and swift peer-review system

Efficient typesetting and proofreading procedure

Display of the result of downloads and visits, as well as the number of cited articles Maximum dissemination of your research work

Submit your manuscript at: http://papersubmission.scirp.org/

Or contact ce@scirp.org 